\title{
Entre un trote en furor y un juego de $\mathrm{X}$ y 0
}

\section{Elizabeth Robles}

Recebido em: 12 de abril de 2019 Aceito em: 04 de maio de 2019
Elizabeth Robles, artista, poeta y educadora puertorriqueña, nació en Camuy y actualmente vive y tiene su taller/estudio en San Juan, Puerto Rico. Posee un bachillerato en Humanidades con concentración en Historia del Arte de la Universidad de Puerto Rico y una maestría en Comunicaciones con concentración en Medios y Cultura Contemporánea de la Universidad del Sagrado Corazón. Su poesía ha sido publicada por La secta de los perros, en revistas electrónicas y en libros de artistas.

Contato: mayavioleta@yahoo.com Puerto Rico 
PALABRAS CLAVE: arte caribeño, colonialismo,ecofeminismo, animismo, performance, arte $y$ escritura, arte $y$ comunidad, arte urbano, arte y resistencia.

\section{KEYWORDS: Caribbean art,} colonialism, ecofeminism, animism, performance, art and writing, art and community, urban art, art and resistance.
Resumen: Narrado en primera persona, la artista ofrece una mirada a la experiencia íntima de dos de sus performances, realizados al caminar las ciudades de Hato Rey y Río Piedras en Puerto Rico. El arte en una colonia caribeña se desborda a las calles; la artista presenta comouna acción doméstica como deshacer trajes o un jueso de apariencia irrelevante, senera actividad comunitaria de encuentro y resistencia.

Abstract: Narrated in the first person, the artist offers a look at the intimate experience of two of her performances, made while walking the cities of Hato Rey and Río Piedras in Puerto Rico. Art in a Caribbean colony overflows the streets; the artist presents how a domestic action such as unstitching dresses or a game of irrelevant appearance, generates community activity of encounters and resistance. 


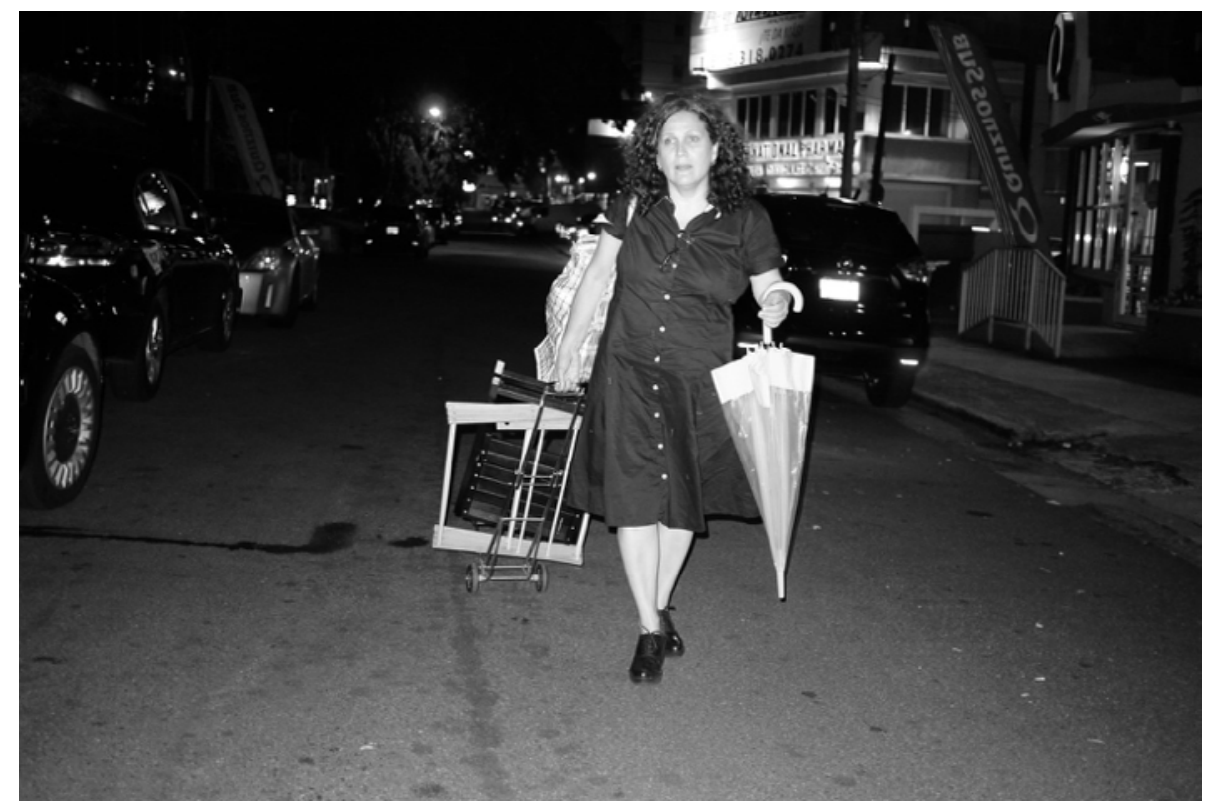

De regreso a casa luego del trote en furor, foto por Máximo Colón

Animada por lo que pueda surgir al pensar juntas durante esta tarde ${ }^{1^{*}}$, comparto con ustedes dos performances: Trote en furor y $X$ y 0 : juego de estrategia en doble. En el performance el presente es el tiempo de la posibilidad: se trata del cuerpo y el tiempo al unísono, en el ahora-aquí. Hacer arte en la calle visibiliza estructuras de poder, la desidia urbana, las ruinas, la usurpación de lo común público, la indiferencia del gobierno evidenteen espacios abiertos; pero, de igual forma, la celebración de convivir, el apoyo ético, la apuesta por la confianza que surge de la vida en común y la sorpresa compartida. 
Ambos, Trote en furor y Xy 0: juego de estrategia en doble, toman sentido $\mathrm{y}$ advierten sobre las condiciones de supervivencia en nuestro momento histórico, político y social. El performance como medio de arte surge de mi práctica de caminar, al margen del mercado del arte. Se trata de un(a) aparecer que no responde a lo que se espera patriarcalmente de la vivencia pública dela mujer en la calle. En ambos se manifestaron estructuras de poder sobre nuestros cuerpos. El espacio público de coexistencia se activa al sabernos implicados, nos enfrenta con el conocimiento y la responsabilidad de saber que existe alguna posibilidad de vivir de otra manera. Aunque conocía el área para Trote en furor, no fue hasta llegar en la mañana al lugar y enfrentar la situación de los autos estacionados sobre la acera cuando pude seleccionar el lugar exacto. Mientras que el performance $X$ y 0 : juego de estrategia en doble depende completamente del azar en el acto de caminar para accionar sobre algún muro. Aunque me preparo para ello, salir a la calle siempre me coloca ante lo inesperado. Siempre está latente un riesgo... un nuevo giro podría ocurrir en cualquier instante. No es posible controlar el potencial de lo que puede pasar, nicómo mi cuerpo lo vivirá, ni las condiciones a la intemperie y mucho menos cómo el espectador y cada ciudadano en la calle reaccionarán.

Trote en furor y $X$ y $O$ son acciones que abren preguntas; operan dejando cosas sin resolver, no lo explican todo. Una vez finaliza la acción quedan reflexiones pendientes tanto para mí como para quienes lo presenciaron. No solo el mensaje es abierto, sino que prácticamente ignoro casi todo lo que el público piensa; o sea, me queda poca certeza de las interpretaciones 
o de la experiencia del público. En estos performances, según va pasando el tiempo, así como también puede darse de inmediato, pero siempre espontáneamente, el espectador actúa ante lo que pasa $-\mathrm{y}$ cuando digo "espectador" me refiero al ciudadano transeúnte o que va en auto; el que trabaja en la zona o camina por ella porque vive cerca: todos integrantes de la comunidad. El contacto del espectador al acercarse lo convierte en partícipe directo en completa libertad de su experiencia.

Ambos performances han acontecido sin anuncio previo como una apuesta para que la acción acontezca ante el público desde sus propias perspectivas. Fuera de marcos artísticos, la mirada toma cierta autonomía por parte de quien los ve, quien puede o no entender lo que acontece como arte. Aquí arte y vida conviven. En estas acciones no soy ni represento un personaje. No se trata de explicar algo, sino de tocar o trastocar los entresijos que nos rodean. Ser es siendo en el devenir mujer de forma más amorfa, más deforme, en un estar que rompe la rutina cotidiana asimilada uniformemente, lo que entiendo permite diversidad de inflexiones.

Trote en furor, performance de 2015, constó de una sola acción: descoser trajes de mujeres durante 12 horas ininterrumpidas; en un horario de 7:00 A.M. a 7:00 P.M. A una cuadra de distancia desde mi residencia al lugar de la acción, frente a una institución médica privada, me senté en un área que quedó sin usurpar por la institución médica que se apropió de la acera para usarla como estacionamiento. 
ENTRE UN TROTE EN FUROR Y UN JUEGO DE X Y O

Elizabeth Robles

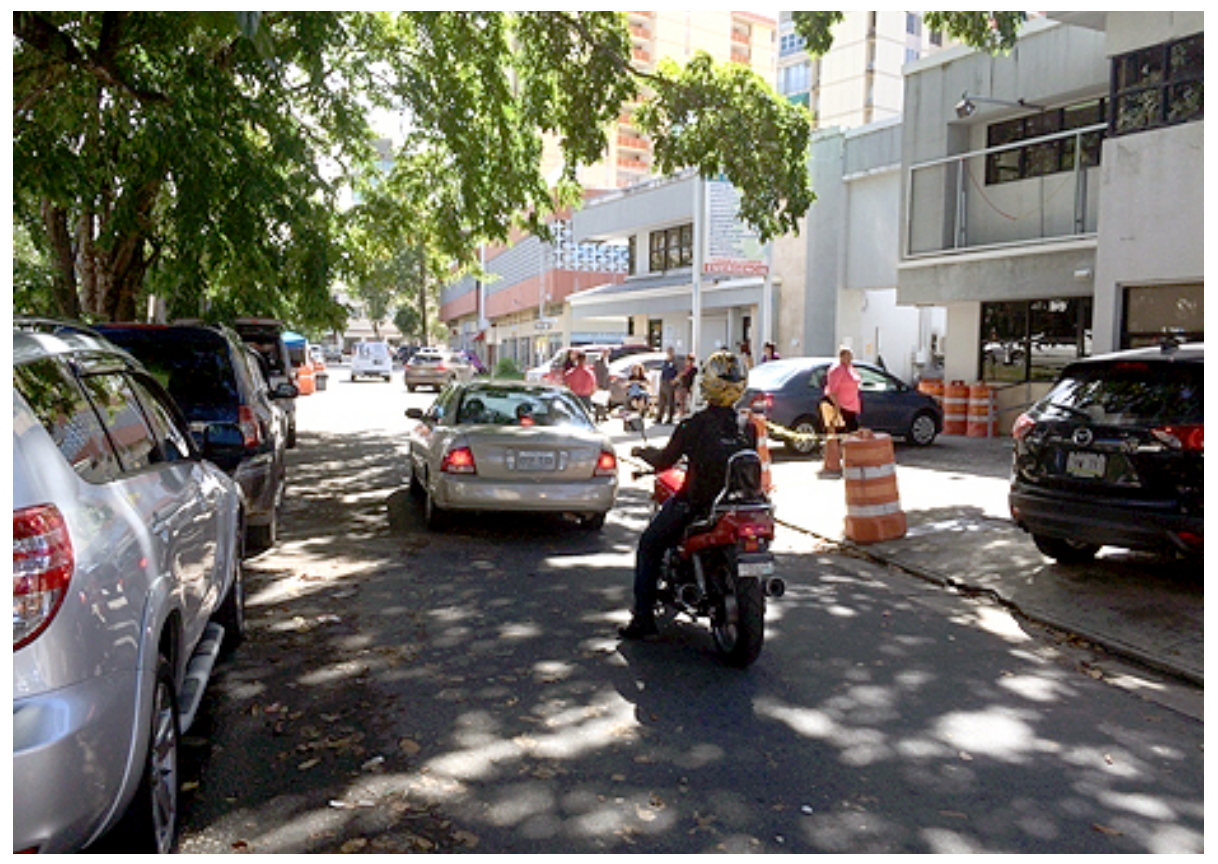

Esta foto y las siguientes fueron tomadas por algunos de los espectadores; suministradas por E.M. Robles

Tomé los cuidados de no impedir al peatón caminar o desplazarse sin peligros, no bloqueé la entrada y salida de los autos en el estacionamiento oficial del dispensario médico. Llevé conmigoun saco con trajes de mujer, una silla desplegable, un tendero, una sombrilla y un des-cosedor.Cada vez que desprendía una pieza de un traje, fuera el cuello, un bolsillo, una manga, la colocaba tendida en el tendero. Mientras descosía, a veces, trotaba con furor mis piernas, pero permaneciendo sentada. 
Mientras estuve allí, trabajando por horas, la gente me contaba de su desempleo, de cómo sus familiares y amigos se habían tenido que ir de Puerto Rico porque no encontraban trabajo. Me hablaron de las precarias y abusivas condiciones de trabajo que vivían o de sus problemas con los planes médicos. Juanita, una señora de altura de poco más de 4', se paró a mi lado y no se movió ni cuando vino la policía ni luego. Allí se quedó, protegiéndome - así me dijo: "yo me quedo aquí, no te preocupes, estoy contigo", y allí se quedó de pie junto a mí por horas. Me habló de sus dientes y de cómo planificaba poder ir al dentista. También me dijo que vivía en una casa alquilada en Hato Rey y que sembraba la tierra, aunque no fuera de ella.

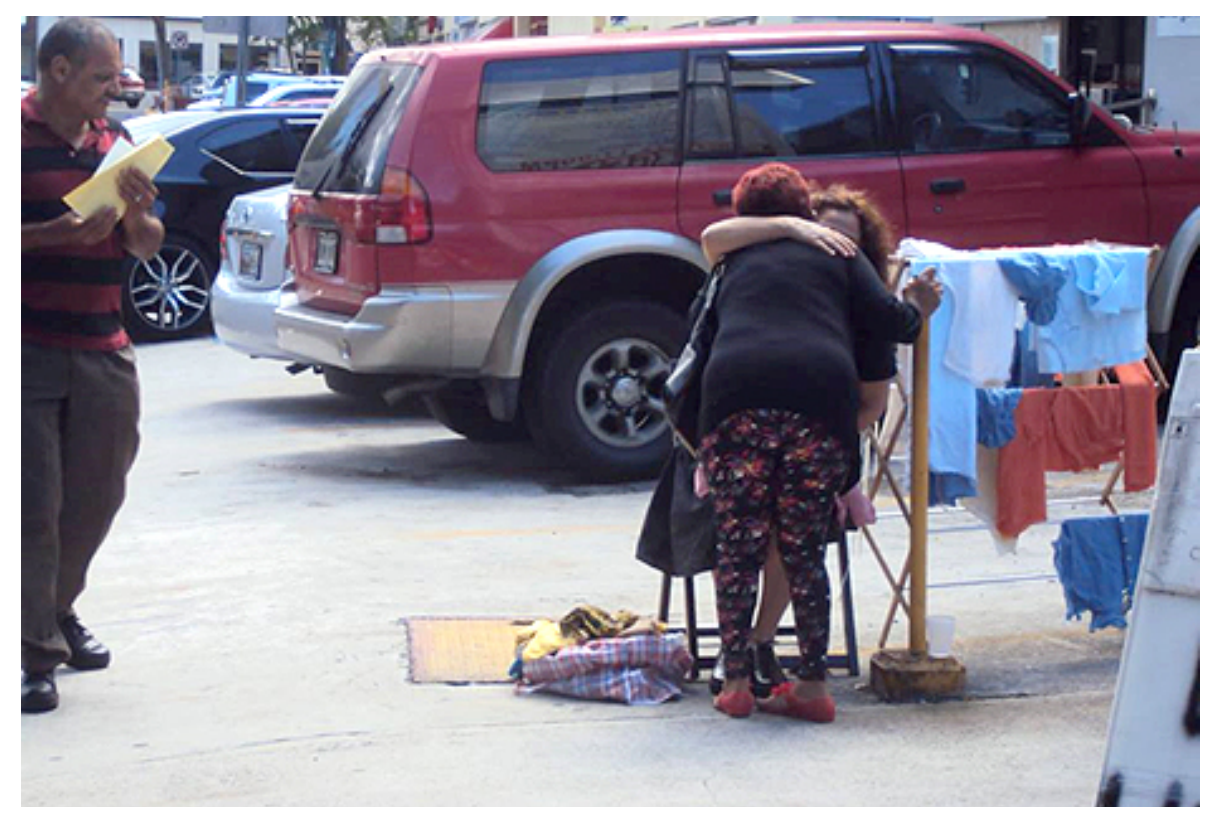


Entre telas y trote, el acto repetitivo por horas de destruir descosiendo unos trajes, trabajando sin que se me pagara, provocó una serie de violencias: como si mi presencia echara algo abajo, mi conducta se detonaba incoherente ante la autoridad. Algo no esperado, algo que no se supone, se hacía visibleen la calle. La seguridad del centro de salud me amedrentó con insinuaciones de amenazas verbales y corpóreas si no me marchaba del lugar; e intentaron, incitándome, a que yo cometiera actos de peligro propio para justificar llamar a la policía. No lo lograron. Sin embargo, la policía llegó endospatrullas y una motora policiaca. Rodeándome, me interrogaron repitiendo la pregunta de si alguien me pagaba. Hicieron que les mostrara mis zapatos y la suela, argumentaban primero que había llovido y yo me había mojado, luego decían que podía hacerme daño estar bajo el sol. Insistían en que les dijera cuántos trajes tenía que descoser. Me decían que debía irme al balcón de mi casa, y hacer mi trabajo allí. Entre tantos otros argumentos me diagnosticaron de locura, pero al final decidieron dejarme allí. Durante las 12 horas de trabajo hablé de destruir y de rehacer. Mi cuerpo era múltiple y condensado en fluidos. Muchas personas que no conocía me hicieron confidencias, otros me trajeron agua y comida - la que yo no podía ingerir, solo tomé unos sorbos de agua durante el tiempo de la acción. A las 7 de noche recogí y me marché a pie hasta mi casa sin saber aún que la policía había querido poner una orden para hospitalizarme.

Inicié el otroperformance - Xy 0: juego de estrategia en doble en el 2018, dedicado a la artista Frieda Medín.Trata de una sola acción en variaciones. 
Voy jugando X y 0 en los muros de la ciudad, siempre a distancia a pie desde mi residencia en Hato Rey hasta llegar y recorrer Río Piedras. Este juego se desarrolla en escritura espejo con ambas manos a la vez.

Ocurre al pasar del tiempo y los meses, a cualquier hora del día, de modo que durará mientras yo viva o hasta que no pueda caminar más. Los resultados del juego siempre son tentativos, sobre todo porque el acto de escritura que surge del performance es uno de los cambios. Juego y escribo frases inesperadas al jugar. El performance se hace siendo; de ahí surge una escritura espontánea que queda como manifiesto en carbón sobre los muros de la ciudad. A veces las frases se repiten y es queno hay presión alguna para innovar.

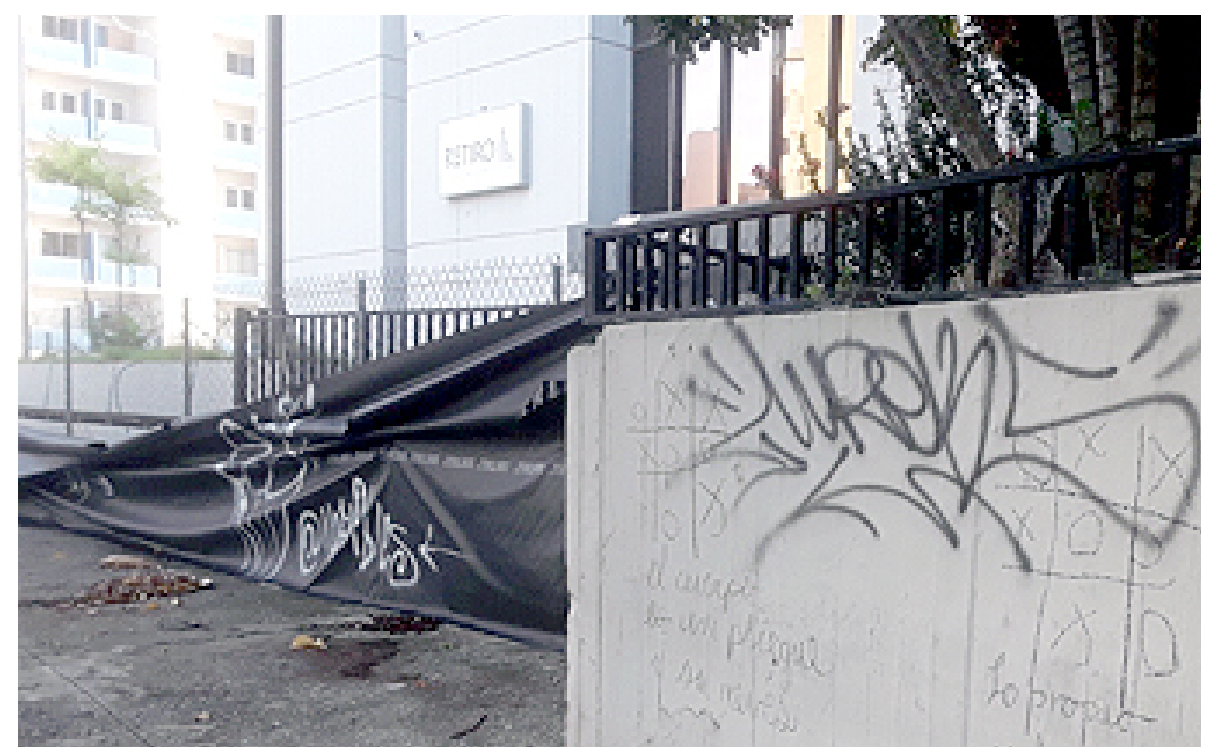

Performance: Jueso de $X$ y $O$ 
La acción gira en torno a un juego de la infancia, un combate de estrategia simple en sus reglas. Una guerra aparentemente pequeña en una cuadrícula de dos líneas rectas verticales y dos horizontales hace que la problemática aparezca. En ellas cada jugada en contra puede desplazarse en vertical, horizontal o diagonal. ¿Qué es ganar o perder? ¿Será que ganar o perder podrían solo ser un tránsito de la imaginación y a la vez nada? ¿Qué condición del cuerpo se nos exige? Hay un trabajo minucioso, riguroso en este juego que acontece por el cuerpo al caminar, un trabajo que apunta a las estructuras de convivencia: estamos implicadas. Caminar como forma de arte suda el cuerpo: continuar haciendo lo mismo; el repetir de la acción conecta con las condiciones forzadas de reproducir la vida y a su vez, estas se rompen en el performance. Lo mismo no es igual dos veces. Siempre pasa por primera vez. Jugarnos la vida es empujar los límites.

¿Qué fuerza nombra el cuerpo que juega y escribe? Hay fatiga por agotamiento y apetito a la vez; en este caminar jugando, ganar y perder, vivir y morir coexisten; la superficie es profunda, el cuerpo se impulsa en el deseo de seguir cuando es posible transformarlo en otro cuerpo. En otra experiencia de vida. Suda mi cuello y la axila. ¿Qué estructura se rompe? Podría parecer un arte sin técnica, al menos sin esa validada por la tradición, sin gesto degracia, un hecho de precariedad y resistencia, y libre de obligaciones. Como artista, hacer un arte que no presupone un valor estético es a su vez buscar que los espectadores vivan la experiencia artística desde sus propias perspectivas. El arte transforma la forma de mirarnos y coexistir. Salir a la calle a hacer arte es a la vez empujar los límites que se 
me imponen como mujer en comunidad; es abrirme al azar de convivir en encuentro, a la posibilidad de activar vínculos.

¿Qué exceso y desafío en cada jugada hacen de este juego, cada vez, uno nuevo y el mismo? Como si me hubiera fugado, al caminar sudo bajo mis senos y la entrepierna. Hay que tirarse a la calle y escribir, aunque se trate de un juegoinacabado, interrumpido y trastocado, a contracorriente, como es $X y 0$, y aun así sensible a lo que aparece y reaparece desde los muros de nuestra ciudad. Caminar activa otro conocimiento del cuerpo; sin exactitud soy una y muchas. Caminar por perder el tiempo huele a resistir. Ir allí donde hay peligro, donde no se supone que estemos, también nos quita el miedo. Es así que cuando juego me detengo y escribo:

¿Cuadrícula, cuadrícula, a quién veo cuando te miro?

Mira, y mira otra vez. Mira algo. Mira otra cosa.

Te volteas y ves.

Juego mientras algo se estropea.

Juego aquí bajo este sol y del otro lado.

El cuerpo es pliegue, fuera y dentro de mí.

A doble salto, descomponlo.

Juego del revés / Me lo juego, no me estorbas.

Ruedo, entre líneas.

Lo propio es lo más extraño.

Ubicuidad íntima, traduce el juego.

Mírate, fija a los ojos.

Ir cruzando al otro lado. A todo su alrededor. Con nada. 
ENTRE UN TROTE EN FUROR Y UN JUEGO DE X Y O

Elizabeth Robles

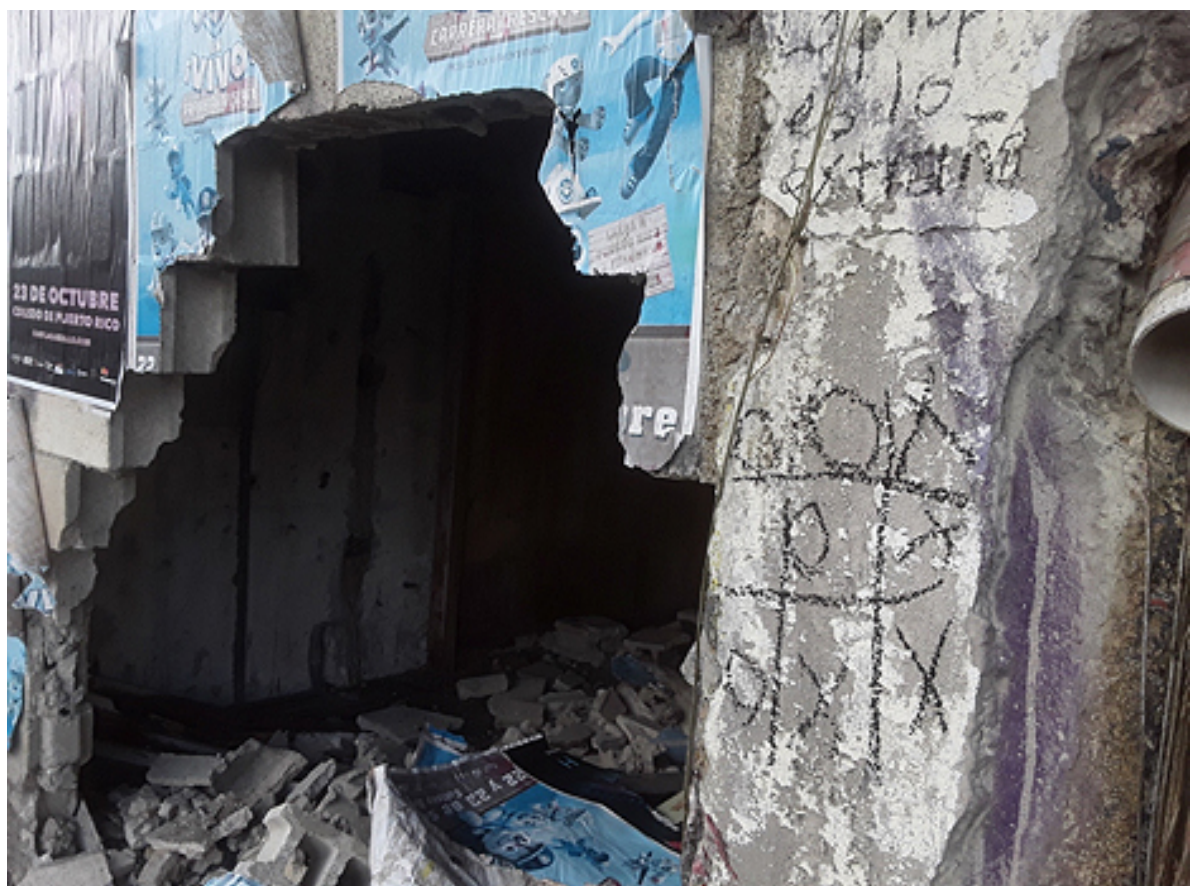

Rumeo de nueve casillas y carbón, cemento brea hollín, la mano ronca juega a doble salto.

El animal en mí en otro redoble, juego a ser.

Parpadeo por ganar, aunque sea de vez en cuando

la cuadrícula retumba; cuerpo, pliegue y su revés.

Con otro cuerpo.

Entra y sal como puedas. 